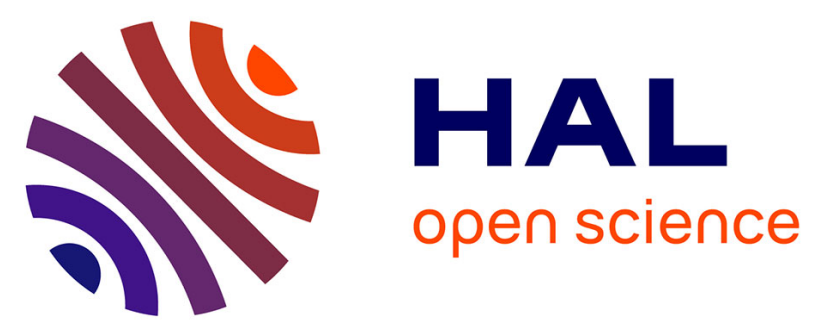

\title{
Extreme events in total ozone over the Northern mid-latitudes: An analysis based on long-term data sets from five European ground-based stations
}

Harald Rieder, L. Jancso, S. Di Rocco, J. Staehelin, Jörg A. Maeder, T. Peter, Mathieu Ribatet, Anthony Davison, Hugo de Backer, Ulf Koehler, et al.

\section{To cite this version:}

Harald Rieder, L. Jancso, S. Di Rocco, J. Staehelin, Jörg A. Maeder, et al.. Extreme events in total ozone over the Northern mid-latitudes: An analysis based on long-term data sets from five European ground-based stations. Tellus B - Chemical and Physical Meteorology, 2011, 63 (5), pp.860-874. 10.1111/j.1600-0889.2011.00575.x . hal-00790119

\section{HAL Id: hal-00790119 \\ https://hal.science/hal-00790119}

Submitted on 31 May 2021

HAL is a multi-disciplinary open access archive for the deposit and dissemination of scientific research documents, whether they are published or not. The documents may come from teaching and research institutions in France or abroad, or from public or private research centers.
L'archive ouverte pluridisciplinaire HAL, est destinée au dépôt et à la diffusion de documents scientifiques de niveau recherche, publiés ou non, émanant des établissements d'enseignement et de recherche français ou étrangers, des laboratoires publics ou privés. 


\section{Extreme events in total ozone over the Northern mid-latitudes: an analysis based on long-term data sets from five European ground-based stations}

Harald E. Rieder, Leonhardt M. Jancso, Stefania Di Rocco, Johannes

Staehelin, Joerg A. Maeder, Thomas Peter, Mathieu Ribatet, Anthony C. Davison, Hugo De Backer, Ulf Koehler, Janusz Krzyścin \& Karel Vaníiček

To cite this article: Harald E. Rieder, Leonhardt M. Jancso, Stefania Di Rocco, Johannes Staehelin, Joerg A. Maeder, Thomas Peter, Mathieu Ribatet, Anthony C. Davison, Hugo De Backer, Ulf Koehler, Janusz Krzyścin \& Karel Vaníiček (2011) Extreme events in total ozone over the Northern mid-latitudes: an analysis based on long-term data sets from five European groundbased stations, Tellus B: Chemical and Physical Meteorology, 63:5, 860-874, DOI: 10.1111/ j.1600-0889.2011.00575.x

To link to this article: https://doi.org/10.1111/j.1600-0889.2011.00575.x

\section{(c) 2011 John Wiley \& Sons A/S}

Submit your article to this journal
Published online: 18 Jan 2017. 


\title{
Extreme events in total ozone over the Northern mid-latitudes: an analysis based on long-term data sets from five European ground-based stations
}

\author{
By HARALD E. RIEDER ${ }^{1 *}$, LEONHARDT M. JANCSO ${ }^{1,2}$, STEFANIA DI ROCCO $^{1,3}$, \\ JOHANNES STAEHELIN ${ }^{1}$, JOERG A. MAEDER ${ }^{1}$, THOMAS PETER ${ }^{1}$, MATHIEU RIBATET ${ }^{4,5}$, \\ ANTHONY C. DAVISON ${ }^{4}$, HUGO DE BACKER ${ }^{6}$, ULF KOEHLER ${ }^{7}$, JANUSZ KRZY ŚCIN ${ }^{8}$ \\ and KA REL VANÍČE K ${ }^{9}, \quad{ }^{1}$ Institute for Atmospheric and Climate Science, ETH Zurich, Zurich, Switzerland; \\ ${ }^{2}$ Institute for Meteorology and Geophysics, University of Innsbruck, Innsbruck, Austria; ${ }^{3}$ Department of Geography, \\ University of Zurich, Zurich, Switzerland; ${ }^{4}$ Mathematics Institute for Analysis and Applications, EPF Lausanne, \\ Lausanne, Switzerland; ${ }^{5}$ Institute of Mathematics and Modeling, University of Montpellier II, Montpellier, France; \\ ${ }^{6}$ Royal Meteorological Institute of Belgium, Brussels, Belgium; ${ }^{7}$ German Meteorological Service (DWD), \\ Meteorological Observatory Hohenpeissenberg, Germany; ${ }^{8}$ Institute of Geophysics, Polish Academy of Sciences, \\ Warsaw, Poland; ${ }^{9}$ Czech Hydrometeorological Institute, Hradec Kralove, Czech Republic
}

(Manuscript received 2 February 2011; in final form 13 June 2011)

\begin{abstract}
We apply methods from extreme value theory to identify extreme events in high (termed EHOs) and low (termed ELOs) total ozone and to describe the distribution tails (i.e. very high and very low values) of five long-term European ground-based total ozone time series. The influence of these extreme events on observed mean values, long-term trends and changes is analysed. The results show a decrease in EHOs and an increase in ELOs during the last decades, and establish that the observed downward trend in column ozone during the 1970-1990s is strongly dominated by changes in the frequency of extreme events. Furthermore, it is shown that clear 'fingerprints' of atmospheric dynamics (NAO, ENSO) and chemistry [ozone depleting substances (ODSs), polar vortex ozone loss] can be found in the frequency distribution of ozone extremes, even if no attribution is possible from standard metrics (e.g. annual mean values). The analysis complements earlier analysis for the world's longest total ozone record at Arosa, Switzerland, confirming and revealing the strong influence of atmospheric dynamics on observed ozone changes. The results provide clear evidence that in addition to ODS, volcanic eruptions and strong/moderate ENSO and NAO events had significant influence on column ozone in the European sector.
\end{abstract}

\section{Introduction}

After the detection of the Antarctic ozone hole in the 1980s (e.g. Farman et al., 1985), downward trends in stratospheric ozone and the linked increase in erythemal UV-radiation (e.g. Calbo et al., 2005) became of major interest within the scientific community and the general public. The successful implementation of the Montreal Protocol (e.g. WMO, 2007) and its expected beneficial effects on the ozone layer (e.g. WMO, 2007; Mäder et al., 2010), led to discussion of the 'recovery' or possible 'superrecovery' of the ozone layer (compared to pre-

\footnotetext{
*Corresponding author; now at Department of Applied Physics and Applied Mathematics, Columbia University, New York, USA.

e-mail: hr2302@columbia.edu

DOI: $10.1111 / \mathrm{j} .1600-0889.2011 .00575 . x$
}

1980s values; e.g. Austin and Wilson, 2006; Eyring et al., 2007; Harris et al., 2008; Shepherd, 2008; Hegglin and Shepherd, 2009; Waugh et al., 2009; Eyring et al., 2010; SPARC-CCMVal, 2010). However, the conclusions of these studies differ and the timing of any recovery and its extent are still under discussion. In previous studies, numerous processes influencing column ozone in the Northern mid-latitudes have been identified, such as the 11yr solar cycle, the Quasi-Biennial Oscillation (QBO), emission of man-made ozone depleting substances (ODSs) and processes such as synoptic-scale meteorological variability (e.g. Dobson and Harrison, 1926; Steinbrecht et al., 1998; Shepherd, 2008), decadal or long-term climate variability (e.g. Hood and Zaff, 1995; Chandra et al., 1996; Hood, 1997), described, for example, by the Northern Atlantic Oscillation (NAO) (e.g. Appenzeller et al., 2000; Orsolini and Doblas-Reyes, 2003), the Arctic Oscillation (AO) (e.g. Thompson and Wallace, 2000), the El 


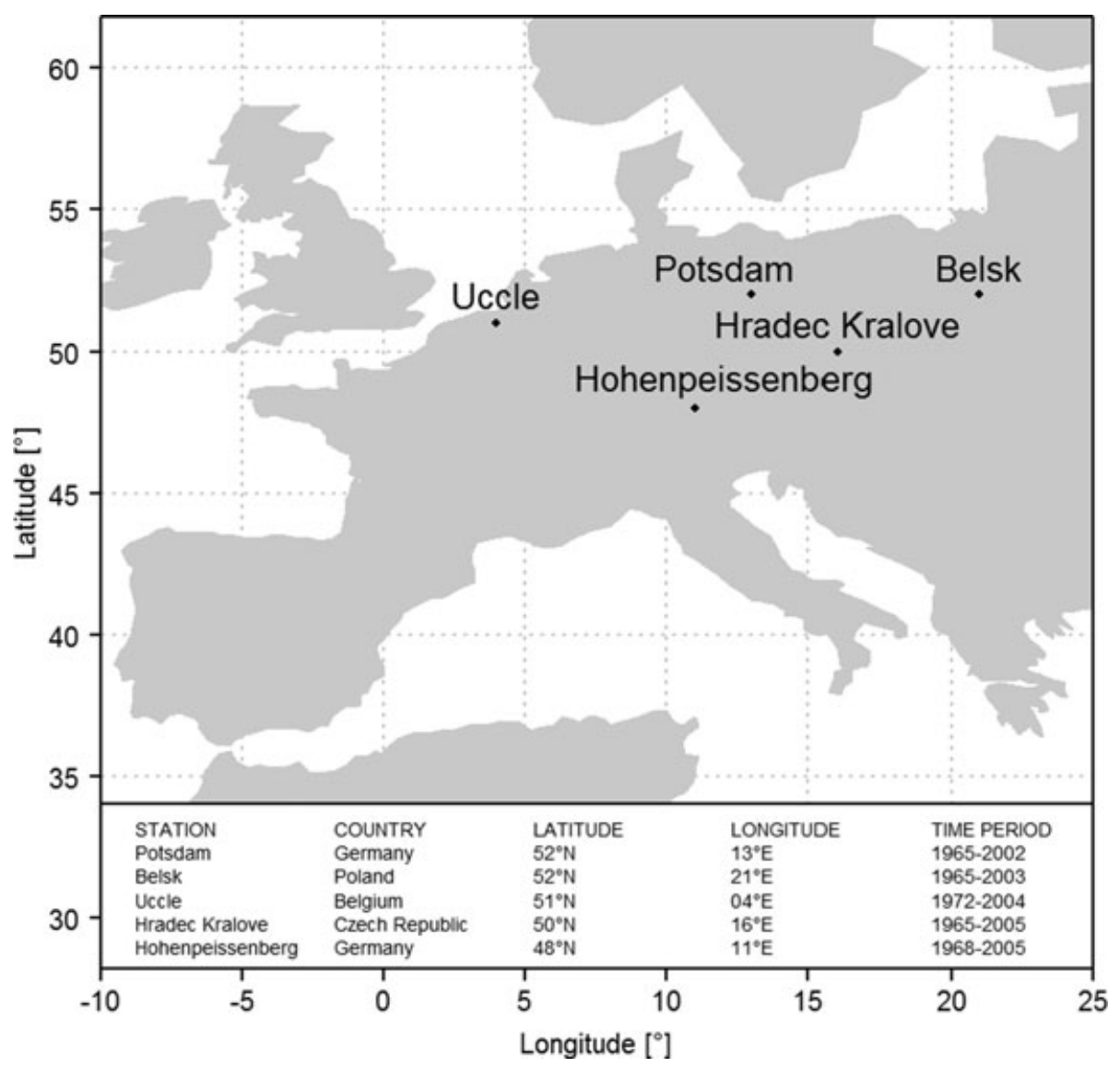

Fig. 1. Station locations in the European sector and station-specific information.

Niño Southern Oscillation (ENSO) (e.g. Brönnimann et al., 2004a) and volcanic eruptions (e.g. Pittock, 1965; Grams and Fiocco, 1967; Jaeger and Wege, 1990; Yue et al., 1991; McCormick et al., 1995; Solomon, 1999; Robock, 2000; Mäder et al., 2007). Column ozone trends were formerly determined from long-term homogenized data series by fitting with multiple linear regression models in which some of these 'explanatory variables' were used to describe the variability of the Earth's atmosphere (e.g. Mäder et al., 2007; Wohltmann et al., 2007). There is broad agreement within the scientific community that observed negative long-term ozone trends between the early 1970s and the mid-1990s at Northern mid-latitudes are dominated by changes in the concentration of the ODSs, whereas short-term changes are dominated by dynamical changes (e.g. horizontal advection, convergence or divergence of mass related to changes in tropospheric and stratospheric pressure systems) (e.g. Harris et al., 2008). Although several studies showed that the atmospheric burden in ODS [mostly described in terms of Equivalent Effective Stratospheric Chlorine (EESC)] had the largest influence on column ozone changes over the Northern mid-latitudes, there is clear evidence that dynamical changes also had a substantial influence (e.g. Mäder et al., 2007; Wohltmann et al., 2007; Harris et al., 2008). There is strong evi- dence that dynamical changes have been more important for ozone changes at Northern mid-latitudes than in other regions of the world (e.g. Appenzeller et al., 2000; Staehelin et al., 2001; WMO, 2003). According to Hood and Soukharev (2005), Wohltmann et al. (2007), Mäder et al. (2007) and Harris et al. (2008), dynamic processes may account for about one third (or more) of the ozone decline starting in the 1970s. The major importance of dynamical changes is also confirmed by studies summarized in Harris et al. (2008) and WMO (2007), which indicate that the recent increase in total ozone in Northern mid-latitudes during the late 1990s is mainly due to dynamic changes. Further studies (e.g. Hood and Soukharev, 2005; Harris et al., 2008; Shepherd, 2008; Hegglin and Shepherd, 2009) reported that the change in the stratospheric burden in ODS (decline since 1997) contributed only insignificantly to the observed ozone increase at Northern mid-latitudes in recent years.

Complementary to regular time series analysis (based on, for example, linear trend estimates retrieved by multiple linear regression models) concepts of extreme value theory (EVT) have been applied in recent studies (Rieder et al., 2010a,b) for the first time in the field of column ozone research, as statistical analysis showed that total ozone data are not adequately described by a Gaussian distribution. Furthermore, the studies of Rieder et al., 
(2010a,b) revealed that clear responses (from here on referred to as 'fingerprints') to dynamical and chemical factors influencing column ozone are found by analysing the distribution tails (i.e. very high and very low values) instead of mean values of total ozone data. In this study, the concept developed by Rieder et al., (2010a,b) for the Arosa (Switzerland) total ozone time series is slightly modified to analyse the frequency distribution of days with extreme low (ELOs) and high (EHOs) total ozone for five long-term European ground-based data sets, in order to explore whether the results found for Arosa can be generalized to other long-term total ozone time series.

\section{Data and methods}

\subsection{Data}

We analyse column ozone measurements (daily mean values) from five long-term European ground-based stations [Uccle (Belgium), Hradec Kralove (Czech Republic), Belsk (Poland), Hohenpeissenberg and Potsdam (both Germany)], all of which contribute to the ground-based total ozone monitoring network of the Global Atmospheric Watch (GAW) of the World Meteorological Organization (WMO). The stations were selected from the World Ozone and Ultraviolet Radiation Data Centre (WOUDC) database (RMIB, CHMI-HK, PAS, DWD-MOHp, DWD-MOP. WOUDC [Data]; retrieved 27 January 2009, from http://www.woudc.org.) using two selection criteria for European sites: (1) more than 35 continuous years of total ozone data in 1965-2005 and (2) complete seasonal coverage within the individual records. Data from the world's longest total ozone record, Arosa (Switzerland), are not included here as this data set was analysed in detail already in earlier work (Rieder et al., 2010a,b), however, in Section 4, results from Arosa are compared with those derived for the stations analysed here. Figure 1 gives the locations of the stations and specific station information and Fig. 2 provides an overview of daily total ozone observations and annual mean values for the individual stations. However, note that presently used data quality control procedures of the GAW program were introduced during the 1970s and 1980s (Basher, 1995), and the data quality of earlier measurements might be lower. In particular, sulphur dioxide is an interference for Dobson measurements and can affect total ozone measurements (e.g. De Backer and De Muer, 1991). Each individual time series was carefully homogenized (see references given in Table 1) and quality of recent data is ensured by comparison campaigns with the world standard instrument(s) (e.g. instrument comparisons at the Regional Dobson Calibration Center at Hohenpeissenberg, Germany).

We restrict our analysis to column ozone measurements obtained by Dobson spectrophotometers: only these measurements extend backward to the 1960s, and data obtained using the more modern Brewer instruments show systematic differences in the seasonal variation compared to the Dobson instrument records

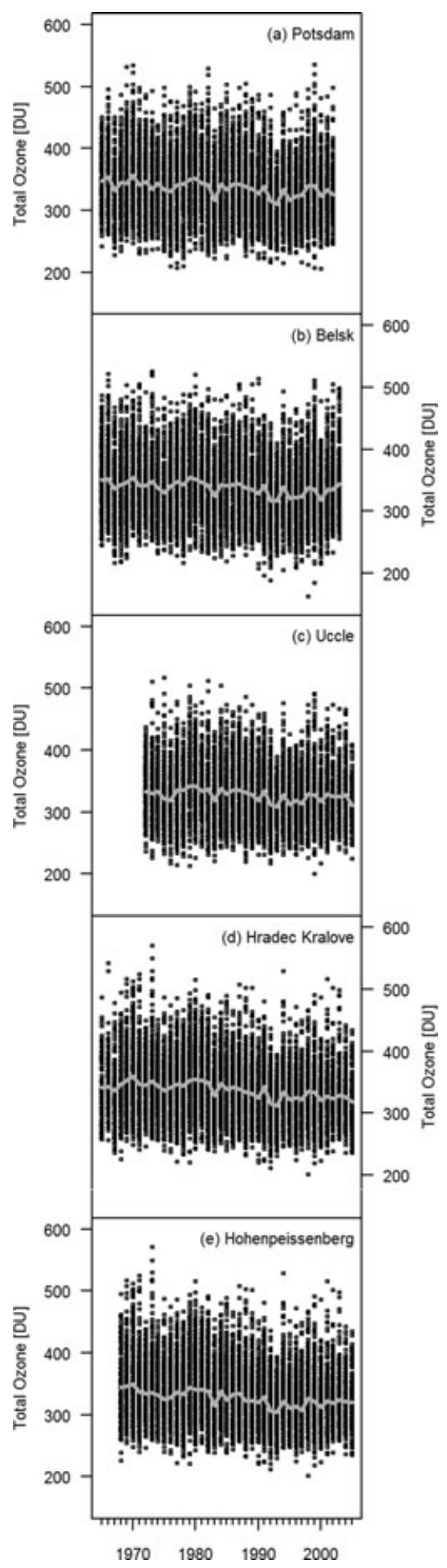

Fig. 2. Daily (dots) and annual (solid line) averages of total ozone at (a) Potsdam, Germany, (b) Belsk, Poland, (c) Uccle, Belgium, (d) Hradec Kralove, Czech Republic and (e) Hohenpeissenberg, Germany. Details on record length of individual time series and specific station information are given in Fig. 1. Measurements have been retrieved from the World Ozone and Ultraviolet Radiation Centre (WOUDC) on 27 January 2009. 
Table 1. Information on the different Dobson time series used and their homogenization

\begin{tabular}{lcl}
\hline Station (instrument) & Date of Homogenisation & Reference \\
\hline Potsdam (D71) & 1999 & Spaenkuch et al. (1999) \\
Belsk (D84) & 1983,1991 & Dziewulska-Eosiowa et al. (1983); Degórska and Rajewska-Więch (1991) \\
Uccle (D40) & 1991 & De Backer and De Muer (1991); De Muer and De Backer (1992) \\
Hradec Kralove (D74) & 2003 & Vaníček et al. (2003) \\
Hohenpeissenberg (D104) & 1995 & Koehler (1995) \\
\hline
\end{tabular}

Table 2. Overview of index data used in this study

\begin{tabular}{|c|c|c|}
\hline Data & Time range (resolution) & Source \\
\hline NINO3.4 Index & 1965-2005 (monthly) & $\begin{array}{l}\text { NCAR/UCAR Climate and Global dynamics } \\
\text { http://www.cgd.ucar.edu/cas/catalog/climind/TNI_N34/ } \\
\text { index.html }\end{array}$ \\
\hline NAO Index & 1965-2005 (seasonal) & $\begin{array}{l}\text { NCAR/UCAR Climate and Global dynamics } \\
\text { http://www.cgd.ucar.edu/cas/jhurrell/indices.html }\end{array}$ \\
\hline SATO Index ${ }^{+}$ & 1965-2000 (monthly) & $\begin{array}{l}\text { NASA Goddard Institute for Space studies } \\
\text { http://data.giss.nasa.gov/modelforce/strataer/ }\end{array}$ \\
\hline ODS (in EESC) & 1965-2000 (monthly) & $\begin{array}{l}\text { NASA Goddard Institute for Space studies } \\
\text { http://acdb-ext.gsfc.nasa.gov/Data_services/automailer/ }\end{array}$ \\
\hline $\begin{array}{l}\text { Polar vortex ozone loss contributions to } \\
\text { Northern mid-latitudes column ozone }\end{array}$ & 1970-2004 (winter averages) & $\begin{array}{l}\text { Wohltmann et al. (2007) (Ingo Wohltmann, personal } \\
\text { communication, 2009) }\end{array}$ \\
\hline
\end{tabular}

Note: Data sets marked with (+) have not been available for the entire time period (1965-2005) analysed.

(e.g. Rajewska-Więch et al., 2006; Scarnato et al., 2010). Furthermore, measurements at some stations include only direct sun measurements whereas the less precise zenith sky measurements are required at most sites to obtain a representative sample (i.e. high number of measurement days) because of less favourable weather conditions. From the five stations analysed in this study, the Dobson record of Hohenpeissenberg includes only direct sun measurements whereas those of the other four stations (Belsk, Hradec Kralove, Potsdam and Uccle) include both direct sun and zenith sky observations.

We used several indices for 'fingerprint' analysis and description of atmospheric dynamics (e.g. ENSO and NAO) and chemistry (volcanic eruptions, ODS in general and polar vortex ozone loss in particular). Table 2 contains an overview of the data sets used (including their sources), and Fig. 3 summarizes the temporal evolution of the single indices describing atmospheric dynamics and chemistry.

\subsection{Methods}

Following Rieder et al. (2010a,b), concepts of EVT have been applied to identify thresholds for low and high total ozone daily mean values and for the analysis of the distribution tails of the five long-term total ozone data sets.

The analysis is based on fitting the Generalized Pareto Distribution (GPD) to the distribution tails of the ozone data (i.e. to very low and high values) on a monthly basis. The GPD is commonly used in the analysis of rare events, as it arises as the natural distribution of the excess of a variable above (below) a sufficiently high (low) threshold (e.g. Davison and Smith, 1990). Asymptotic arguments (e.g. Pickands, 1975; Coles, 2001) justify the use of the GPD for modelling extremes, as the GPD is the limiting distribution of normalized excesses beyond a threshold, as the threshold approaches the endpoint of the distribution. The GPD (see eq. 1) of a variable $x$ (here, column ozone) is defined by three parameters, the threshold value $u$, the scale parameter $\sigma$ and the shape parameter $\xi$

$$
\begin{aligned}
& F(x)=1-\left[1+\xi \frac{x-u}{\sigma}\right]^{-1 / \xi} ; \\
& \sigma>0, x>u, 1+\xi \frac{x-u}{\sigma}>0,
\end{aligned}
$$

where $u$ defines which values of the variable $x$ (here, column ozone) can be considered as extremes, $\xi$ determines the shape of the tail of the distribution and $\sigma$ is a measure of the spread of the distribution [with the same dimensions as the variable $x$, here Dobson Units (DU) for column ozone]. In the application, the GPD is fitted to the distribution tails (i.e. very high and low values) of daily total ozone data at the five stations. Threshold estimation is based on mean residual life plots, threshold choice plots and threshold evaluation (based on Quantile-Quantile comparison of observed and modelled extremes and density plots). To address autocorrelation in daily total ozone data, a declustering procedure (following Davison and Smith, 1990) was applied 


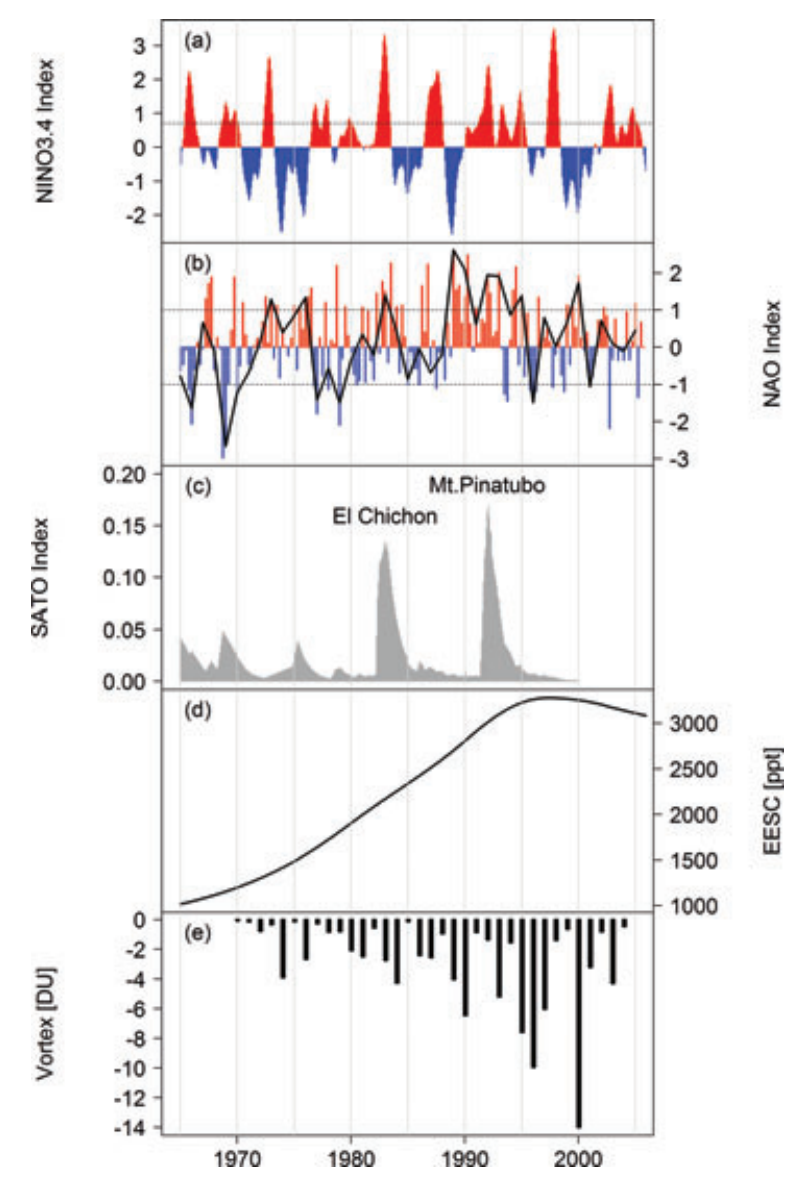

Fig. 3. Indices for (a) El Niño Southern Oscillation (ENSO), monthly NINO3.4 Index, vertical dotted line marks 0.7 values, (b) North Atlantic Oscillation, seasonal NAO Index (principal components of the leading empirically determined orthogonal function of seasonal sea level pressure anomalies over the Atlantic sector $\left(20-80^{\circ} \mathrm{N}\right.$, $90^{\circ} \mathrm{W}-40^{\circ} \mathrm{E}$ ), solid black line shows NAO Index for DJFM, vertical dotted lines marks \pm 1 values and (c) volcanic aerosol loading in terms of mean optical thickness at $550 \mathrm{~nm}$, monthly Northern Hemispheric Sato Index (Sato et al., 1993; major volcanic eruptions of El Chichón (1982) and Mt Pinatubo (1991) are marked). (d) Atmospheric loading of ODS in terms of Equivalent Effective Stratospheric Chlorine (EESC) on monthly basis. (e) Estimates of the contribution of ozone destruction in the polar vortex to column ozone at the Northern mid-latitudes in late winter and spring (in DU) (data from Wohltmann et al. (2007), I. Wohltmann, personal communication, 2009). For data sets of indices used, see Table 2.

to identify clusters of extremes. Within those clusters (defined as consecutive exceedances above/below a certain threshold $u$ ) only the maximum (minimum) was used in the analysis. Thresholds for low and high column ozone are selected on monthly basis. To avoid monthly leaps, monthly threshold values are extrapolated to daily values by linear interpolation. Sensitivity analysis for the Arosa total ozone time series showed (see Rieder et al., 2010a and their supplementary material) that the time period used for determination of thresholds for ELOs and EHOs does not substantially affect the frequency of ELOs and EHOs and therefore does not affect the robustness of the fingerprint analysis and other results. Thresholds were derived for each station. All available data were included in the threshold selection process. An overview of daily thresholds for low and high total ozone and corresponding monthly mean values for the individual stations is presented in Fig. 4. For further details on the threshold selection process, the use of mean residual life plots, threshold choice plots, Quantile-Quantile comparison and density plots as well as sensitivity of threshold estimates on time windows chosen for threshold estimation, see the methodology section and the supplementary material in Rieder et al. (2010a).

\section{Results and discussion}

\subsection{Frequency of extreme events in total ozone}

Following Rieder et al. (2010a,b), column ozone data are split into three categories: days with extreme high total ozone (termed EHOs), days with extreme low total ozone (termed ELOs) and not extreme days (NEOs). The observed frequency of EHOs, ELOs and NEOs (on annual basis) at the five stations is plotted in Fig. 5. Expected and observed dynamical and chemical effects on total ozone are discussed, in detail, in the scientific literature (see Section 3.2), applying this knowledge 'fingerprints' are deduced from the frequency distribution of ELOs and EHOs (by visual inspection) and compared to annual mean values (see Fig. 6). The results confirm the findings of Rieder et al. (2010b) that 'fingerprints' are discernible in the extremes part of the time series even if no attribution is feasible from the analysis of annual mean values.

\subsection{Atmospheric dynamics and chemistry}

The section summarizes the main features of the variables leading to changes in column ozone over the Northern mid-latitudes (especially, the European sector); for extended discussion of covariates, see Rieder et al. (2010b). Below, the results on annual basis are discussed in detail for the individual stations. The results for the individual seasons are similar to those found for Arosa (see Rieder et al., 2010b) and therefore are not discussed in detail.

3.2.1. Volcanic eruptions. Volcanic eruptions influence column ozone through heterogeneous processes and heating (change in transport) in the lower stratosphere (LS). Through volcanic eruptions gaseous compounds including $\mathrm{SO}_{2}, \mathrm{H}_{2} \mathrm{~S}$ and $\mathrm{HCl}$ enter the stratosphere (e.g. Staehelin et al., 2001). The sulfur containing species are quickly oxidized to sulphuric acid. Sulphuric acid aerosols can influence stratospheric ozone by (1) altering stratospheric dynamics due to infrared absorptivity leading to a heating of the LS (e.g. Brasseur and Granier, 1992; Kodera, 1994; Hadjinicolaou et al., 1997) and (2) by 
Fig. 4. Thresholds for days with extreme low (ELOs) and high (EHOs) total ozone and corresponding monthly means at (a) Potsdam, Germany, (b) Belsk, Poland, (c) Uccle, Belgium, (d) Hradec Kralove, Czech Republic and (e) Hohenpeissenberg, Germany.
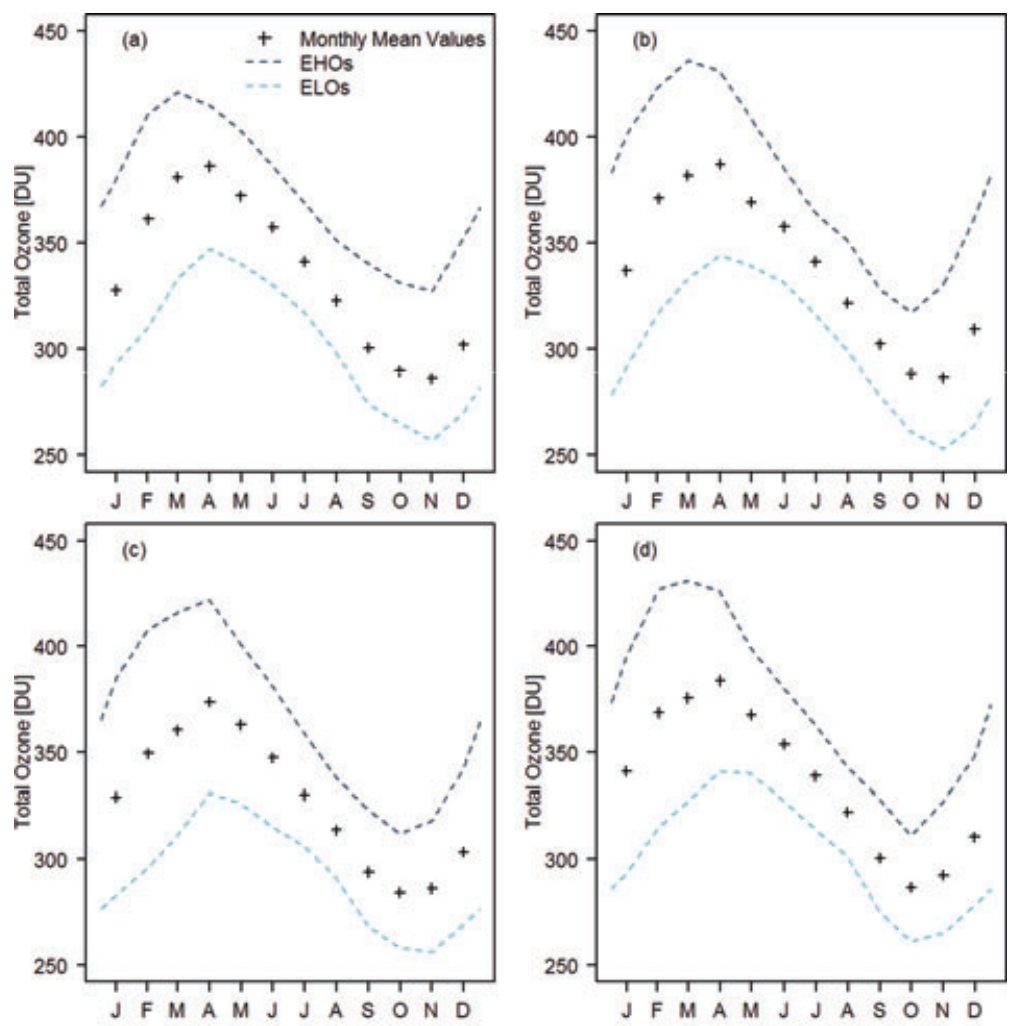

influencing chemistry in the LS as they provide surfaces for heterogeneous ozone destruction (e.g. Peter, 1997; Solomon, 1999). The SATO Index describing the aerosol load in terms of mean optical thickness is strongly enhanced after the two major volcanic eruptions of the last century (El Chichón in March/April 1982 and the Mt Pinatubo in June 1991) (Fig. 3c). For all the stations analysed, clear 'fingerprints' can be found for both eruptions in 1983 and 1992-1993 as the frequency of ELOs is strongly increased whereas that of EHOs is strongly reduced (Fig. 5).

3.2.2. Strong polar vortex ozone loss and ozone depleting substances. The atmospheric burden in ODSs increased from the 1950s onward due to enhanced industrial production of chlorofluorocarbons (CFCs) (e.g. Molina and Rowland, 1974; Rowland and Molina, 1975). The Montreal Protocol for the protection of the ozone layer was signed in 1987, followed by several amendments (e.g. Staehelin et al., 2001; WMO, 2003; WMO, 2007). Due to the benefit of the Montreal Protocol, stratospheric ODS-concentrations declined in the late 1990s (peak values were reached in 1997, see Fig. 3). A recent study by Mäder et al. (2010) provides evidence that this decline in ODS has also had measurable effects on column ozone changes. Equivalent Effective Stratospheric Chlorine (EESC), the weighted sum of chlorine and bromine containing species, is commonly used to describe the chemical effects of ODS on the ozone layer (WMO, 2003). The temporal evolution in EESC is shown in Fig. 3d. In the polar region, ozone depletion is propelled by heterogeneous chemistry on PSCs in winter and early spring (as ozone loss on polar stratospheric clouds (PSCs) is caused by chain reactions involving activated chlorine (e.g. Peter, 1997; Solomon, 1999). Polar ozone loss affects also the mid-latitudes due to 

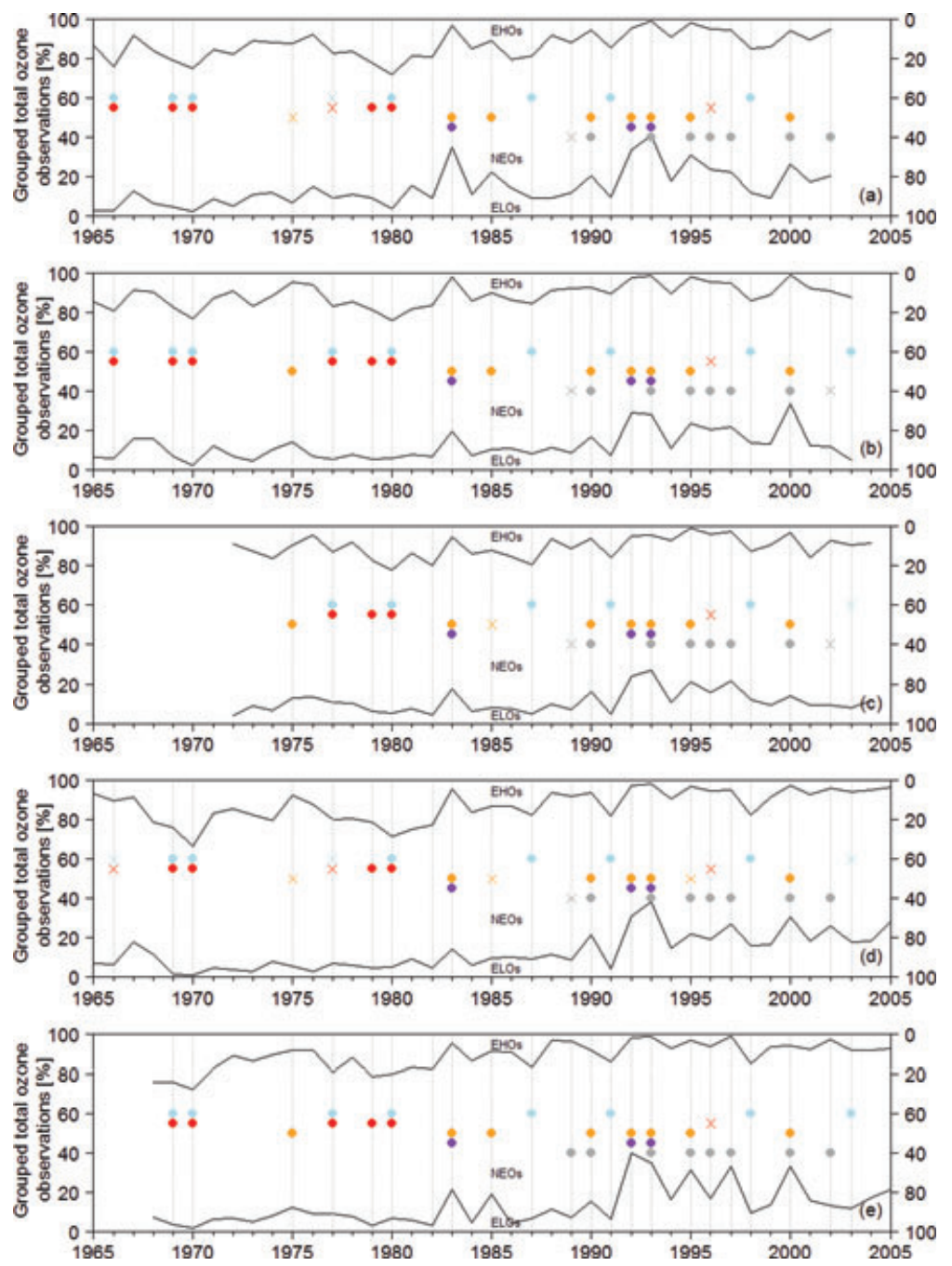

Fig. 5. Time series of annual frequency of days with extreme low (ELOs, left axis) and high (EHOs, right axis) total ozone and 'fingerprints' of atmospheric dynamics and chemistry as visible therein for (a) Potsdam, Germany, (b) Belsk, Poland, (c) Uccle, Belgium, (d) Hradec Kralove, Czech Republic and (e) Hohenpeissenberg, Germany. For convenient reference, the area between the ELO and EHO curves shows the fraction of not extreme days (NEOs). Coloured marks show global modes distinguished by the following indices: ENSO (light blue), NAO- (red), NAO+ (orange), volcanic eruptions of El Chichón and Mt Pinatubo (purple), polar vortex ozone loss (grey). Filled circles denote 'fingerprints' attributable to events and crosses denote events not resulting in a clear 'fingerprint.' mixing of polar air masses after the vortex breakdown in Northern spring (e.g. Knudsen and Grooss, 2000; Fioletov and Shepherd, 2005). Proxy data for contributions of polar vortex ozone loss to the Northern mid-latitudes were taken from Wohltmann et al. (2007). The temporal evolution of this polar vortex ozone loss index is shown in Fig. 3e. On annual basis, 'fingerprints' of polar vortex ozone loss are clearly visible throughout the five stations in 1989-1990, 1993, 1995-1997, 2000 and 2002 (besides Belsk and Uccle) (Fig. 5).

3.2.3. El Niño Southern Oscillation (ENSO). The El Niño Southern Oscillation phenomenon influences the climate system and weather through large-scale interactions between the ocean and the atmosphere (Diaz and Markgraf, 2000). Warm ENSO events (El Niño) are triggered by a strong contrast between high tropical and low extratropical Pacific sea surface temperature (SST) (e.g. Brönnimann et al., 2004a,b). This influences the Hadley circulation and Rossby wave generation at the North Pacific and surrounding areas (e.g. Trenberth et al., 1998; Alexander et al., 2002). The warm ENSO winter signal consists of cold temperatures over Northern Europe, high sea level pressure from Iceland to Scandinavia and low sea level pressure over Central and Western Europe (e.g. Friedrich and Müller, 1992; Merkel and Latif, 2002; Graetbatch et al., 2004). Warm ENSO events cause more frequent stratospheric warming episodes, which weaken the polar vortex as a stronger wave activity flux diminishes the vortex strength (and hence polar vortex ozone loss) (e.g. van Loon and Labitzke, 1987; Labitzke and van Loon, 1999), which leads to a stronger descent over the polar region, and strengthens the meridional circulation in the middle stratosphere, leading to enhanced ozone transport from the tropics to the extra tropics and resulting in higher ozone values in late winter and early spring (Newman et al., 2001; Randel et al., 2002).

Figure 3a shows the Nino 3.4 Index, which describes the monthly SST anomaly from its long-term mean average over the NINO 3.4 region. During the warm phase, (El Niño), SST in the eastern equatorial Pacific is higher and western tropical Pacific SST is lower than normal. La Niña is the opposite 
Fig. 6. 'Fingerprints' of atmospheric dynamics and chemistry as visible in the annual averages of column ozone at (a) Potsdam, Germany, (b) Belsk, Poland, (c) Uccle, Belgium, (d) Hradec Kralove, Czech Republic and (e) Hohenpeissenberg, Germany. Coloured marks show global modes distinguished by the following indices: ENSO (light blue), NAO- (red), $\mathrm{NAO}+$ (orange), volcanic eruptions of $\mathrm{El}$ Chichón and Mt. Pinatubo (purple), polar vortex ozone loss (grey). Filled circles denote 'fingerprints' attributable to events and crosses denote events not resulting in a clear 'fingerprint.'
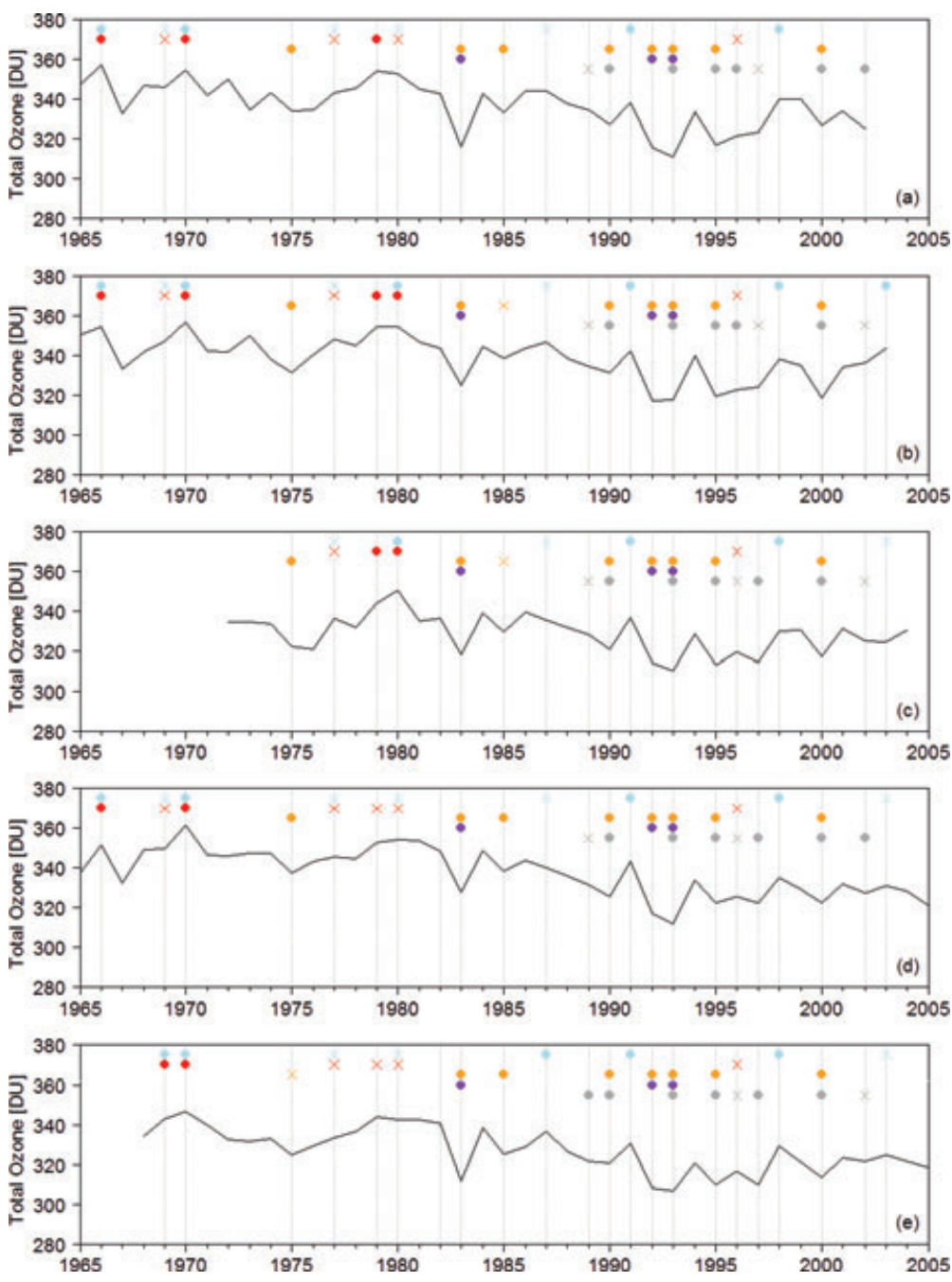

phenomenon and is usually shorter and less intense. 'Fingerprints' of several El Niño events (NINO 3.4 Index larger than 0.7) are visible in the frequency distribution of EHOs (see Fig. 5) at all stations. On annual basis, 'fingerprints' of moderate/strong ENSO events are found in 1966 (no data available at Uccle and Hohenpeissenberg), 1969-1970 (no data available at Uccle), 1977 (besides Potsdam and Hradec Kralove), 1980, 1987, 1991, 1998 and 2003 (at Belsk and Hohenpeissenberg) (see Fig. 5). Our findings confirm the results from Rieder et al. (2010b) that moderate/strong El Niño events (NINO 3.4 Index larger than 0.7) have a significant influence on total ozone in the European sector.

3.2.4. North Atlantic Oscillation. A large fraction of the interannual/decadal variability in tropospheric meteorology and lower stratospheric dynamics in the Northern Hemisphere can be explained by changes in the North Atlantic Oscillation (NAO) (pressure difference at sea level between the Icelandic low and the Azores high), the weakening of the Brewer-Dobson circulation, the strengthening of the Arctic polar vortex and changes in tropopause height and temperature in the LS (e.g. Hurrell, 1995; Steinbrecht et al., 1998; Thompson and Wallace, 1998; Pawson and Naujokat, 1999; Randel and Wu, 1999; Newman and Nash, 2000; Wallace, 2000). These changes have also a significant influence on column ozone over the Northern Hemisphere. The NAO also strongly affects European winter climate and the strength of the Arctic polar vortex (e.g. Appenzeller et al., 2000; Thompson and Wallace, 2000; Orsolini and Limpasuvan, 2001; Hadjinicolaou et al., 2002; Orsolini and Doblas-Reyes, 2003).

North Atlantic Oscillation influence is revealed in changes in the direction and intensity of the westerly tropospheric jet stream over the Atlantic (e.g. Orsolini and Limpasuvan, 2001) and changes in storm-track variability across the North Atlantic in cold periods (e.g. Lau, 1988). Positive NAO events are characterized by higher tropopause pressure at high latitudes/lower mid-latitudes and an enhanced Icelandic low (e.g. Appenzeller et al., 2000). This results in higher ozone values over Labrador/southern Greenland and lower ozone values over 
Europe (Orsolini and Doblas-Reyes, 2003). A weak Icelandic low and strong Azores high indicate the negative phase of the NAO, which leads correspondingly to enhanced column ozone over Europe (e.g. Brönnimann et al., 2004a,b). North Atlantic Oscillation modes have changed in recent decades and the polar vortex has strengthened, concomitant with a slower BrewerDobson Circulation leading to lower ozone at high latitudes (e.g. Hurrell, 1995; Appenzeller et al., 2000; Thompson and Wallace, 2000). The temporal evolution of the NAO Index (principal components of the leading empirically determined orthogonal function of seasonal sea level pressure anomalies over the Atlantic sector $\left(20^{\circ}-80^{\circ} \mathrm{N}, 90^{\circ} \mathrm{W}-40^{\circ} \mathrm{E}\right)$ is shown in Fig. $3 \mathrm{~b}$. Various 'fingerprints' of the NAO (during the positive phase the frequency of ELOs increases, whereas during the negative phase the frequency of EHOs increases) are visible from the records (see Fig. 5). 'Fingerprints' of the NAO in the positive phase (NAO+) are found for 1975 (besides Potsdam and Hradec Kralove), 1983, 1985 (besides Hradec Kralove and Uccle), 1990, 1992-1993, 1995 (besides Hradec Kralove) and 2000, whereas 'fingerprints' of NAO in the negative phase (NAO-) are found for 1966 and 1969-1970 (no data at Uccle), 1977 (besides Potsdam and Hradec Kralove) and 1979-1980 (see Fig. 5). Overall, spatial 'fingerprints' can be identified more coherently for the NAO in positive phase (frequency distribution of ELOs) than for the NAO in the negative phase.

\section{Influence of extreme events on observed means and trends in total ozone}

The influence of ELO and EHO events on observed means and trends is quantified by excluding (1) the ELOs, (2) the EHOs, and (3) both ELOs and EHOs from the entire series of the five stations. Here, we find that for all the stations, mean values, trends and long-term changes are strongly influenced by extreme events. This agrees with data for Arosa presented in Rieder et al. (2010b), showing that extreme events are important for long-term trends in the European sector. In Fig. 7 panels (a), (c), (e), (g) and (i) show annual averages of (1) observed, (2) ELOs removed, (3) EHOs removed and (4) both ELOs and EHOs removed total ozone at the five stations. In all cases, total ozone time series show less variability and smoother temporal evolution after removing the extremes, which therefore have a strong impact on the variability of annual (and seasonal) averages in total ozone. To illustrate this schematically, Fig. 7 panels (b), (d), (f), (h) and (k) show LOESS smoothed [Locally weighted Scatterplot Smoothing method (LOESS); Cleveland, 1979; Cleveland and Devlin, 1988] (smoothing parameter $q=$ $2 / 3$ applied) versions of the observed- and extremes-removed annual averages shown in the corresponding panels (a), (c), (e), (g) and (i). From this comparison, we see that all the observations show a steeper decline with time than the extremes-removed averages.

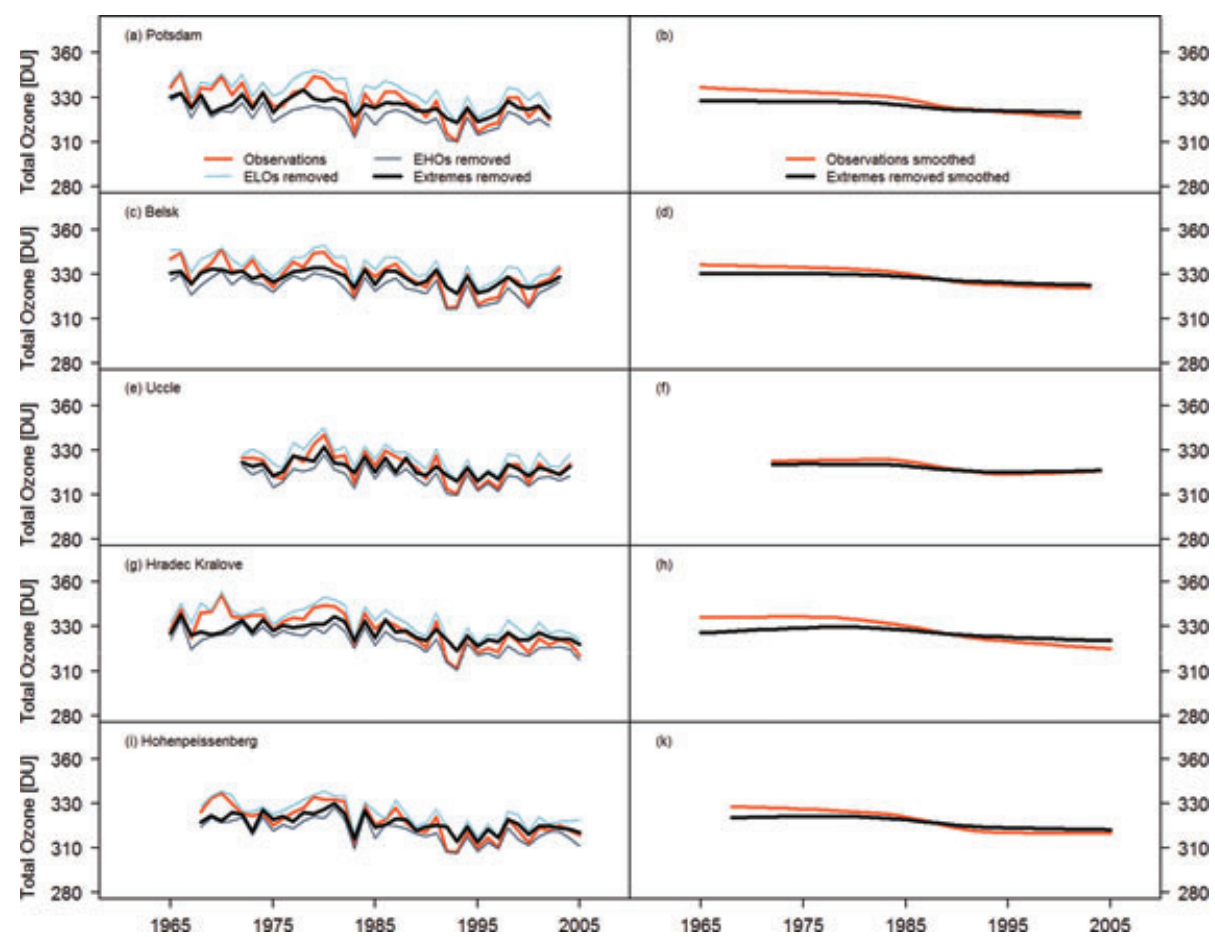

Fig. 7. Observed, ELOs-removed, EHOs-removed and all extremes removed annual averages of total ozone at (a) Potsdam, Germany, (c) Belsk, Poland, (e) Uccle, Belgium, (g) Hradec Kralove, Czech Republic, (i) Hohenpeissenberg, Germany. (b), (d), (f), (h) and (k) LOESS smoothed (LOcally wEighted Scatterplot Smoothing) (with smoothing parameter $\mathrm{q}=2 / 3$ ) observed and extremes removed annual averages of corresponding data shown in (a), (c), (e), (g) and (i). 
Table 3 Annual and seasonal trends (in \% per decade) for 1970-1990 at Potsdam (Germany), Belsk (Poland), Uccle (Belgium), Hradec Kralove (Czech Republic), Hohenpeissenberg (Germany) and Arosa (Switzerland, data from Rieder et al., 2010b) for the observed and extremes removed time series

\begin{tabular}{|c|c|c|c|c|c|}
\hline \multirow[b]{2}{*}{ Station } & & \multicolumn{4}{|c|}{ Trend (in \% per decade) for $1970-1990$} \\
\hline & & Observations & $\begin{array}{c}\text { Time series } \\
\text { without extremes }\end{array}$ & $\begin{array}{c}\text { Time series } \\
\text { without EHOs }\end{array}$ & $\begin{array}{c}\text { Time series } \\
\text { without ELOs }\end{array}$ \\
\hline \multirow[t]{5}{*}{ Potsdam } & Annual & $-1.7( \pm 0.9)$ & $-0.7( \pm 0.5)$ & $-1.0( \pm 0.6)$ & $-1.2( \pm 0.7)$ \\
\hline & Spring & $-2.9( \pm 1.3)$ & $-1.0( \pm 0.5)$ & $-1.8( \pm 0.8)$ & $-2.0( \pm 1.0)$ \\
\hline & Summer & $-2.1( \pm 0.9)$ & $-0.9( \pm 0.5)$ & $-1.6( \pm 0.7)$ & $-1.3( \pm 0.7)$ \\
\hline & Autumn & $-1.8( \pm 0.9)$ & $-0.9( \pm 0.5)$ & $-1.2( \pm 0.8)$ & $-1.4( \pm 0.6)$ \\
\hline & Winter & $1.4( \pm 1.7)$ & $0.6( \pm 0.9)$ & $0.5( \pm 1.2)$ & $1.4( \pm 1.3)$ \\
\hline \multirow[t]{5}{*}{ Belsk } & Annual & $-1.4( \pm 0.8)$ & $-0.7( \pm 0.4)$ & $-1.0( \pm 0.5)$ & $-1.0( \pm 0.7)$ \\
\hline & Spring & $-1.3( \pm 1.2)$ & $-0.7( \pm 0.7)$ & $-0.8( \pm 0.9)$ & $-1.2( \pm 1.0)$ \\
\hline & Summer & $0.8( \pm 0.8)$ & $0.9( \pm 0.6)$ & $1.1( \pm 0.7)$ & $0.7( \pm 0.7)$ \\
\hline & Autumn & $-2.3( \pm 0.8)$ & $-1.1( \pm 0.4)$ & $-1.5( \pm 0.6)$ & $-2.0( \pm 0.7)$ \\
\hline & Winter & $-2.2( \pm 1.6)$ & $-0.5( \pm 0.8)$ & $-1.5( \pm 1.0)$ & $-1.1( \pm 1.4)$ \\
\hline \multirow[t]{5}{*}{ Uccle $^{\mathrm{a}}$} & Annual & $-0.5( \pm 1.1)$ & $-0.5( \pm 0.7)$ & $-0.4( \pm 0.8)$ & $-0.5( \pm 0.9)$ \\
\hline & Spring & $-0.2( \pm 1.5)$ & $0.2( \pm 0.9)$ & $0.5( \pm 0.9)$ & $-0.6( \pm 1.5)$ \\
\hline & Summer & $-0.0( \pm 1.0)$ & $0.0( \pm 0.9)$ & $-0.2( \pm 1.0)$ & $0.3( \pm 1.0)$ \\
\hline & Autumn & $-0.3( \pm 1.3)$ & $-0.2( \pm 0.7)$ & $0.4( \pm 1.0)$ & $-0.9( \pm 1.0)$ \\
\hline & Winter & $-0.7( \pm 1.8)$ & $-0.7( \pm 1.1)$ & $-1.2( \pm 1.4)$ & $-0.2( \pm 1.5)$ \\
\hline \multirow[t]{5}{*}{ Hradec Kralove } & Annual & $-2.5( \pm 0.8)$ & $-0.8( \pm 0.5)$ & $-1.4( \pm 0.5)$ & $-1.8( \pm 0.7)$ \\
\hline & Spring & $-3.5( \pm 1.2)$ & $-1.2( \pm 0.6)$ & $-1.8( \pm 0.8)$ & $-2.9( \pm 1.1)$ \\
\hline & Summer & $-1.5( \pm 0.7)$ & $-0.5( \pm 0.5)$ & $-0.9( \pm 0.5)$ & $-1.0( \pm 0.6)$ \\
\hline & Autumn & $-2.2( \pm 0.8)$ & $-1.2( \pm 0.5)$ & $-1.5( \pm 0.6)$ & $-1.8( \pm 0.7)$ \\
\hline & Winter & $-2.7( \pm 1.6)$ & $-0.6( \pm 1.0)$ & $-1.7( \pm 1.1)$ & $-1.6( \pm 1.4)$ \\
\hline \multirow[t]{5}{*}{ Hohenpeissenberg } & Annual & $-1.8( \pm 0.9)$ & $-0.8( \pm 0.6)$ & $-1.0( \pm 0.7)$ & $-1.7( \pm 0.8)$ \\
\hline & Spring & $-2.9( \pm 1.5)$ & $-1.0( \pm 0.9)$ & $-1.5( \pm 1.0)$ & $-2.3( \pm 1.3)$ \\
\hline & Summer & $-0.8( \pm 0.7)$ & $-0.6( \pm 0.5)$ & $-0.4( \pm 0.6)$ & $-1.0( \pm 0.6)$ \\
\hline & Autumn & $-1.6( \pm 0.8)$ & $-1.4( \pm 0.5)$ & $-1.2( \pm 0.6)$ & $-1.8( \pm 0.7)$ \\
\hline & Winter & $-2.4( \pm 1.4)$ & $-0.7( \pm 0.9)$ & $-1.8( \pm 1.1)$ & $-1.2( \pm 1.1)$ \\
\hline \multirow[t]{5}{*}{ Arosa } & Annual & $-2.4( \pm 0.5)$ & $-0.9( \pm 0.3)$ & $-1.3( \pm 0.6)$ & $-2( \pm 0.5)$ \\
\hline & Spring & $-3.4( \pm 1.0)$ & $-0.9( \pm 0.5)$ & $-1.5( \pm 0.7)$ & $-2.9( \pm 0.8)$ \\
\hline & Summer & $-1.5( \pm 0.5)$ & $-0.9( \pm 0.3)$ & $-1.0( \pm 0.5)$ & $-1.2( \pm 0.5)$ \\
\hline & Autumn & $-1.6( \pm 0.7)$ & $-0.8( \pm 0.3)$ & $-0.6( \pm 0.4)$ & $-1.5( \pm 0.6)$ \\
\hline & Winter & $-2.8( \pm 1.1)$ & $-0.7( \pm 0.7)$ & $-1.8( \pm 0.9)$ & $-1.1( \pm 1.0)$ \\
\hline
\end{tabular}

Note: Standard errors are given within parentheses.

a Due to missing data, before 1972 trends for Uccle have been calculated for 1972-1990.

Tables 3 and 4 provide quantitative information on annual and seasonal ozone trends at the five stations analysed in this study. Simple linear trends for (1) the observational data, (2) data with ELOs excluded, (3) data with EHOs excluded and (4) both ELOs and EHOs excluded, are calculated for the time periods 1970-1990 (see Table 3) and 1980-2000 (see Table 4) for annual and seasonal mean values. For comparison, data for Arosa provided in Rieder et al. (2010b) are included in Tables 3 and 4.

For all stations, decadal trends are (as expected) more negative for the years 1980-2000 due to the strong decline in column ozone at Northern mid-latitudes following the Mt. Pinatubo eruption. However, trend reduction between the entire observed time series and the extremes-removed time series is similar for both periods, 1970-1990 and 1980-2000, showing the major influence of EHOs and ELOs on ozone changes and trends. Total ozone trends on an annual basis are reduced on average by a factor of about 2, while seasonal trends are reduced on average by about a factor of 2.5 in winter, by about a factor of 2 in spring, and a factor of about 1.5 in summer and autumn when the extremes are removed from the ozone records.

The downward trends determined by simple linear regression show differences among the six European ground-based time series (see Tables 3, 4 and Fig. 7), perhaps partly due to lower data quality in the earlier measurements, before the gradual introduction of more rigorous data quality control in the GAW (see Section 2.1). Therefore, all time series needed careful homogenization. In particular, $\mathrm{SO}_{2}$ pollution influenced the early 
Table 4. Annual and seasonal trends (in \% per decade) for 1980-2000 at Potsdam (Germany), Belsk (Poland), Uccle (Belgium), Hradec Kralove (Czech Republic), Hohenpeissenberg (Germany) and Arosa (Switzerland, calculated from data from Rieder et al., 2010b) for the observed and extremes removed time series

\begin{tabular}{|c|c|c|c|c|c|}
\hline \multirow[b]{2}{*}{ Station } & & \multicolumn{4}{|c|}{ Trend (in $\%$ per decade) for $1980-2000$} \\
\hline & & Observations & $\begin{array}{c}\text { Time series } \\
\text { without extremes }\end{array}$ & $\begin{array}{c}\text { Time series } \\
\text { without EHOs }\end{array}$ & $\begin{array}{c}\text { Time series } \\
\text { without ELOs }\end{array}$ \\
\hline \multirow[t]{5}{*}{ Potsdam } & Annual & $-2.5( \pm 1.1)$ & $-1.0( \pm 0.5)$ & $-1.2( \pm 0.8)$ & $-2.3( \pm 0.8)$ \\
\hline & Spring & $-4.2( \pm 1.4)$ & $-1.6( \pm 0.6)$ & $-2.5( \pm 1.0)$ & $-3.2( \pm 0.9)$ \\
\hline & Summer & $-1.4( \pm 1.1)$ & $-0.6( \pm 0.5)$ & $-0.7( \pm 0.8)$ & $-1.2( \pm 0.8)$ \\
\hline & Autumn & $-1.2( \pm 1.0)$ & $-0.6( \pm 0.6)$ & $-0.7( \pm 0.7)$ & $-1.1( \pm 0.8)$ \\
\hline & Winter & $-2.9( \pm 1.8)$ & $-1.7( \pm 0.8)$ & $-2.0( \pm 1.2)$ & $-2.3( \pm 1.3)$ \\
\hline \multirow[t]{5}{*}{ Belsk } & Annual & $-3.3( \pm 0.9)$ & $-1.4( \pm 0.5)$ & $-2.3( \pm 0.7)$ & $-2.4( \pm 0.8)$ \\
\hline & Spring & $-4.1( \pm 1.3)$ & $-1.9( \pm 0.7)$ & $-3.0( \pm 1.0)$ & $-3.0( \pm 1.0)$ \\
\hline & Summer & $-3.0( \pm 0.9)$ & $-1.6( \pm 0.7)$ & $-1.9( \pm 0.8)$ & $-2.7( \pm 0.8)$ \\
\hline & Autumn & $-1.6( \pm 0.9)$ & $-0.8( \pm 0.5)$ & $-1.4( \pm 0.6)$ & $-1.0( \pm 0.7)$ \\
\hline & Winter & $-3.9( \pm 1.8)$ & $-1.5( \pm 0.8)$ & $-3.5( \pm 1.2)$ & $-1.8( \pm 1.4)$ \\
\hline \multirow[t]{5}{*}{ Uccle } & Annual & $-3.1( \pm 1.0)$ & $-1.6( \pm 0.6)$ & $-2.0( \pm 0.7)$ & $-2.6( \pm 0.8)$ \\
\hline & Spring & $-3.3( \pm 1.5)$ & $-1.7( \pm 0.8)$ & $-2.6( \pm 1.0)$ & $-2.4( \pm 1.2)$ \\
\hline & Summer & $-1.7( \pm 0.8)$ & $-0.7( \pm 0.5)$ & $-1.0( \pm 0.6)$ & $-1.2( \pm 0.7)$ \\
\hline & Autumn & $-0.7( \pm 0.7)$ & $0.3( \pm 0.3)$ & $0.5( \pm 0.4)$ & $-0.9( \pm 0.7)$ \\
\hline & Winter & $-2.9( \pm 1.6)$ & $-1.4( \pm 0.7)$ & $-1.9( \pm 1.2)$ & $-2.2( \pm 1.2)$ \\
\hline \multirow[t]{5}{*}{ Hradec Kralove } & Annual & $-3.9( \pm 0.9)$ & $-1.9( \pm 0.5)$ & $-2.7( \pm 0.6)$ & $-3.1( \pm 0.8)$ \\
\hline & Spring & $-5.4( \pm 1.3)$ & $-3.0( \pm 0.7)$ & $-4.0( \pm 1.0)$ & $-4.2( \pm 1.0)$ \\
\hline & Summer & $-4.0( \pm 0.8)$ & $-1.9( \pm 0.5)$ & $-2.6( \pm 0.6)$ & $-3.3( \pm 0.7)$ \\
\hline & Autumn & $-1.6( \pm 0.9)$ & $-0.9( \pm 0.5)$ & $-1.4( \pm 0.7)$ & $-1.1( \pm 0.8)$ \\
\hline & Winter & $-4.5( \pm 1.7)$ & $-2.7( \pm 0.9)$ & $-4.3( \pm 1.2)$ & $-2.8( \pm 1.4)$ \\
\hline \multirow[t]{5}{*}{ Hohenpeissenberg } & Annual & $-3.7( \pm 1.0)$ & $-1.9( \pm 0.7)$ & $-2.8( \pm 0.8)$ & $-2.8( \pm 0.9)$ \\
\hline & Spring & $-5.1( \pm 1.5)$ & $-2.8( \pm 0.8)$ & $-4.1( \pm 1.2)$ & $-3.9( \pm 1.1)$ \\
\hline & Summer & $-2.8( \pm 0.8)$ & $-1.9( \pm 0.5)$ & $-2.3( \pm 0.8)$ & $-2.2( \pm 0.6)$ \\
\hline & Autumn & $-0.7( \pm 0.6)$ & $-0.3( \pm 0.3)$ & $-0.9( \pm 0.7)$ & $-0.2( \pm 0.2)$ \\
\hline & Winter & $-5.5( \pm 1.5)$ & $-2.4( \pm 0.9)$ & $-1.8( \pm 1.3)$ & $-1.2( \pm 1.1)$ \\
\hline \multirow[t]{5}{*}{ Arosa } & Annual & $-2.8( \pm 0.8)$ & $-1.1( \pm 0.6)$ & $-1.6( \pm 0.6)$ & $-1.8( \pm 0.8)$ \\
\hline & Spring & $-4.2( \pm 1.3)$ & $-1.9( \pm 0.5)$ & $-3.3( \pm 1.1)$ & $-2.4( \pm 1.0)$ \\
\hline & Summer & $-1.8( \pm 0.6)$ & $-0.8( \pm 0.4)$ & $-1.2( \pm 0.5)$ & $-1.1( \pm 0.5)$ \\
\hline & Autumn & $-0.6( \pm 0.4)$ & $-0.2( \pm 0.2)$ & $-0.5( \pm 0.4)$ & $-0.2( \pm 0.2)$ \\
\hline & Winter & $-3.9( \pm 1.4)$ & $-1.5( \pm 0.6)$ & $-3.1( \pm 1.0)$ & $-2.6( \pm 1.1)$ \\
\hline
\end{tabular}

Note: Standard errors are given within parentheses.

measurement time period for the Uccle time series (e.g. De Backer and De Muer, 1991), and therefore trend analysis has to be interpreted with care.

Numerous EHOs are attributable to ENSO and NAO (in its negative phase) and ELOs are often associated with NAO (in its positive phase) and volcanic eruptions. The overall effect of ODS and the polar vortex loss can be detected in the frequency of EHOs and in the frequency of ELOs. Other effects, such as the solar cycle and the QBO, are not considered in this study as they are expected to have a rather small effect in the European sector and especially regarding extremes.

To quantify the importance of extremes in low and high total ozone for the individual stations, the influences of ELOs (eq. 2) and EHOs (eq. 3) on annual and seasonal averages were calculated:

$I_{\mathrm{ELOs}(t)}=M_{\mathrm{STATION}(t)}-M_{\mathrm{ELOs}(\mathrm{ex})(t)}$,

$I_{\mathrm{EHOs}(t)}=M_{\mathrm{STATION}(t)}-M_{\mathrm{EHOs}(\mathrm{ex})(t)}$.

Here, $I_{\mathrm{ELOs}}\left(I_{\mathrm{EHOs}}\right)$ is the influence of ELOs (EHOs) on total ozone mean values, $M_{\mathrm{ELOs}(\mathrm{ex})}\left(M_{\mathrm{EHOs}(\mathrm{ex})}\right)$ is the average total ozone with ELOs (EHOs) excluded from the time series, $M_{\text {STATION }}$ denotes the average total ozone observed over the corresponding station (Potsdam, Belsk, Uccle, Hradec Kralove or Hohenpeissenberg) and $t$ denotes the averaging time period (seasonal or annual). 


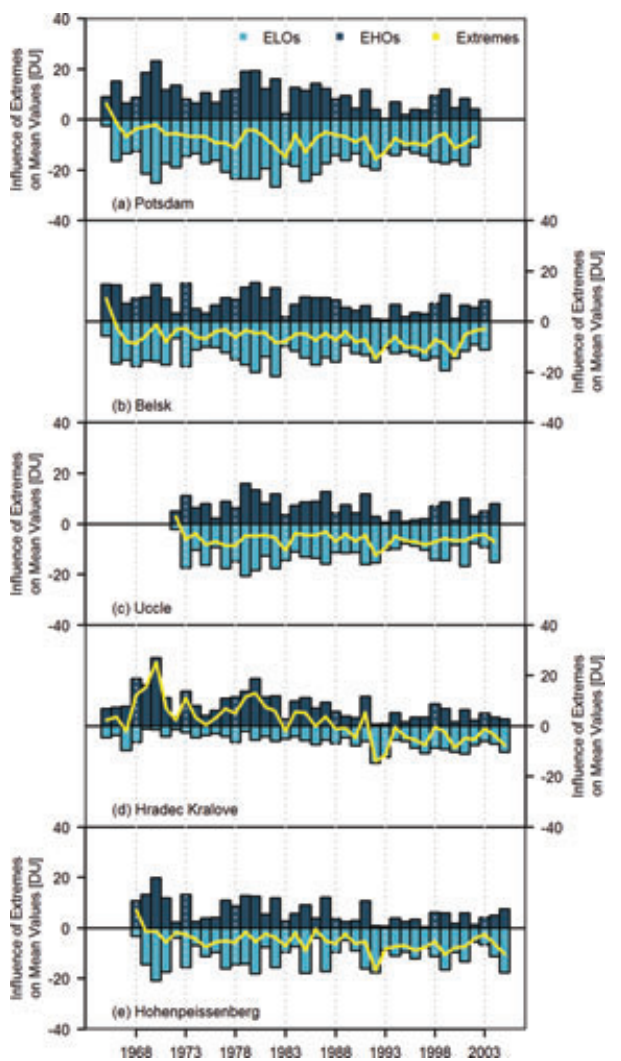

Fig. 8. Influence (according to eqs (2) and (3)) of ELOs (light coloured histogram) and EHOs (dark coloured histogram) and of both extremes (solid line) in DU/year on annual means of total ozone over (a) Potsdam, Germany, (b) Belsk, Poland, (c) Uccle, Belgium, (d) Hradec Kralove, Czech Republic and (e) Hohenpeissenberg, Germany.

The averaged influence of EHOs on mean values of total ozone is $8 \mathrm{DU}$ (largest at Potsdam $10 \mathrm{DU}$, lowest at Hohenpeissenberg $6 \mathrm{DU})$, whereas the averaged influence of ELOs on mean values of total ozone is -12 DU (largest at Potsdam -17 DU, lowest at Hradec Kralove -6 DU). The influence of ELOs, EHOs and both types of extremes on annual basis is shown for the individual stations in Fig. 8. The first decades of the Hradec Kralove record are dominated by the influence of EHOs while at all other stations, a dominating influence of ELOs is found. A possible explanation for this might be a reduced influence of air masses transported to Europe from the Atlantic sector at Hradec Kralove. Trajectory analysis and spatial modelling, though beyond the scope of the presented analysis, could possibly allow for a more detailed characterization of the slightly different behaviour at the stations. Strong influence of ELOs ( $<-25$ DU) and/or EHOs ( $>25$ DU) is found at (almost) all stations in years with strong NAO [influencing in positive phase (NAO+) the ELOs/in negative phase (NAO-) the EHOs] and/or strong ENSO and/or contributions of polar vortex ozone loss. The influence of ELOs and EHOs on observed mean values is strongest in winter and spring season.

\section{Conclusions and discussion}

In this study, methods from EVT have been applied to five longterm European ground-based data sets. The results are in broad agreement with those of Rieder et al. (2010b) for the time series of Arosa. 'Fingerprints' of atmospheric dynamics and chemistry are discernible in the extremes of the time series even if no attribution from mean value analysis is possible. The results confirm also that even moderate ENSO and NAO events have a significant influence on column ozone changes in the European sector. Influence of major volcanic eruptions on column ozone was reported before in the scientific literature, but the results presented here confirm that the influence of volcanic eruptions can be identified in both distribution tails of the time series (increase in the frequency of ELOs and erosion in the frequency of EHOs). A clear attribution of the effect of dynamical and chemical features is difficult as they can occur simultaneously, partly amplifying or compensating each other. However, the results of the presented analysis and earlier work from Rieder et al. (2010b) show that dynamical features influence column ozone strongly and more frequently than previously thought. From a dynamical perspective, EHOs are indicative for northerly advection of $\mathrm{O}_{3}$-rich air masses from the high-latitude lowermost stratosphere and southerly advection of $\mathrm{O}_{3}$-rich air in the middle stratosphere. Conversely, ELOs are indicative for southerly winds with $\mathrm{O}_{3}$-poor air masses from the region of the subtropical jet in the lowermost stratosphere and northerly advection of $\mathrm{O}_{3}$-poor air masses in the middle stratosphere (e.g. Koch et al., 2005). The observed decrease in the frequency of EHOs and corresponding increase in the frequency of ELOs, starting from the late 1970s, is in general agreement with the notion that the polar regime shrank and the tropical band widened over the last decades (e.g. Hudson et al., 2006; Seidel et al., 2008). In previous studies, the dynamical contributions to total ozone changes have been estimated to be 1/3 (or even higher) (Hood and Soukharev, 2003; WMO, 2007; Wohltmann et al., 2007; Harris et al., 2008). From the responses of column ozone to changes in NAO and El Niño as found in the 'fingerprint' analysis, we conclude that our results [and also earlier ones for Arosa (Rieder et al., 2010b)] are in general agreement with these studies. Additionally, further studies repeating the analysis for other long-term ground-based time series at Northern mid-latitudes outside of the European sector (i.e. North American and Asian stations) or satellite time series could contribute to answer the question on how much of column ozone trends are due to changes in dynamical processes and/or due to ODS. The influence of ELOs and EHOs on mean values is variable in time; strong influence of the extremes can be directly related to the occurrence of specific dynamical and/or chemical features. On average, the influence of ELOs was larger than that of EHOs, though both strongly influence variability and observed trends and changes in column ozone; on average, trends are reduced by a factor of about 2 if extremes are removed from the observational data sets. Our results confirm 
that EVT is a useful tool in the analysis of total ozone time series, which helps to attribute patterns and medium to short-range changes to dynamical and chemical factors, thereby providing additional and deeper insight into time series properties than given by conventional time series analysis based on standard metrics.

\section{Acknowledgments}

HER, JS, JAM, MR and ACD acknowledge funding by the Competence Centre for the Environment and Sustainability (CCES) within the ETH-domain in Switzerland within the project EXTREMES: 'Spatial extremes and environmental sustainability: Statistical methods and applications in geophysics and the environment.' KV acknowledges funding by the Czech Grant Agency (GACR) project P209/10/0058 'Long-term changes of the ozone layer over the territory of the Czech Republic.' The authors are grateful to Ingo Wohltmann for providing data on polar vortex contributions to ozone loss in the Northern mid-latitudes. The Software R (R Development Core Team, http://www.rproject.org) was used for the statistical analysis. The authors are grateful to two anonymous referees for their useful comments that helped to improve the quality of the manuscript.

\section{References}

Alexander, M. J., Tsuda, T. and Vincent, R. A. 2002. Latitudinal variations observed in gravity waves with short vertical wavelengths. J. Atmos. Sci. 59, 1394-1404.

Appenzeller, C., Weiss, A. K. and Staehelin, J. 2000. North Atlantic oscillation modulates total ozone winter trends. Geophys. Res. Lett. 27, 1131-1134.

Austin, J. and Wilson, R. J. 2006. Ensemble simulations of the decline and recovery of stratospheric ozone. J. Geophys. Res.-Atmos. 111, D16314, doi:10.1029/2005JD006907.

Basher, R. E. 1995. Survey of the WMO-sponsored Dobson spectrophotometer intercomparisons, Report 19, Global Atmospheric Watch, Global Ozone Research and Monitoring Project. World Meteorological Organization (WMO), Geneva.

Brasseur, G. and Granier, C. 1992. Mount Pinatubo aerosols, chlorofluorocarbons and ozone depletion. Science 257, 1239-1242.

Brönnimann, S., Luterbacher, J., Staehelin, J. and Svendby, T. M. 2004a. An extreme anomaly in stratospheric ozone over Europe in 1940-1942. Geophys. Res. Lett. 31, L08101, doi:10.1038/ nature02982.

Brönnimann, S., Luterbacher, J., Staehelin, J., Svendby, T. M., Hansen, G. and co-authors. 2004b. Extreme climate of the global troposphere and stratosphere in 1940-42 related to El Nino. Nature 431, 971974.

Calbo, J., Pages, D. and Gonzalez, J. A. 2005. Empirical studies of cloud effects on UV radiation: a review. Rev. Geophys. 43, RG2002, doi:10.1029/2004RG000155.

Chandra, S., Varotsos, C. and Flynn, L. E. 1996. The mid-latitude total ozone trends in the northern hemisphere. Geophys. Res. Lett. 23, $555-558$.
Cleveland, W. S. 1979. Robust locally weighted regression and smoothing scatterplots. J. Am. Stat.l Assoc. 74, 829-836.

Cleveland, W. S. and Devlin, S. J. 1988. Locally weighted regressionan approach to regression analysis by local fitting. J. Am. Stat. Assoc. 83, 596-610.

Coles, S. 2001. An Introduction to Statistical Modeling of Extreme Values. London, Springer.

Davison, A. C. and Smith, R. L. 1990. Models for exceedances over high thresholds (with discussion). J. R. Stat. Soc., Ser. B 52, 393-442.

De Backer, H. and De Muer, D. 1991. Intercomparison of total ozone data measured with Dobson and Brewer ozone spectrophotometers at Uccle (Belgium) from January 1984 to March 1991, including zenith sky observations. J. Geophys. Res.-Atmos. 96, 20711-20719.

De Muer, D. and De Backer, H. 1992. Revision of 20 years of Dobson total ozone data at Uccle (Belgium) - fictitious Dobson total ozone trends induced by sulfur-dioxide trends. J. Geophys. Res.-Atmos. 97, 5921-5937.

Degórska, M. and Rajewska-Więch, B. 1991. A Retrospective Reevaluation of Total Ozone and Umkehr Profile Data from Belsk, Poland, Publication of the Institute of Geophysics Polish Academy of Sciences, Poland, 71-76.

Diaz, H. and Markgraf, V. 2000. El Nino and the Southern Oscillation: multiscale Variability and Global and Regional Impacts. Cambridge Univ. Press, Cambridge, UK.

Dobson, G. M. B. and Harrison, D. N. 1926. Measurements of the amount of ozone in the earth's atmosphere and its relation to other geophysical conditions. Proc. R. Soc. Lond. Ser. A-Containing Papers of a Mathematical and Physical Character 110, 660-693.

Dziewulska-Łosiowa, A., Degórska, M. and Rajewska-Więch, B. 1983. The Normalized Total Ozone Data Record, Belsk, 1963-1983. Publication of the Institute of Geophysics Polish Academy of Sciences, Poland, 23-73.

Eyring, V., Waugh, D. W., Bodeker, G. E., Cordero, E., Akiyoshi, H. and co-authors. 2007. Multimodel projections of stratospheric ozone in the 21st century. J. Geophys. Res. D16303, doi:10.1029/2006JD008332.

Eyring, V., Cionni, I., Bodeker, G. E., Charlton-Perez, A. J., Kinnison, D. E. and co-authors. 2010. Multi-model assessment of stratospheric ozone return dates and ozone recovery in CCMVal-2 models. Atmos. Chem. Phys. 10, 9451-9472.

Farman, J. C., Gardiner, B. G. and Shanklin, J. D. 1985. Large losses of total ozone in Antarctica reveal seasonal CLOX/NOX interaction. Nature 315, 207-210.

Fioletov, V. E. and Shepherd, T. G. 2005. Summertime total ozone variations over middle and polar latitudes. Geophys. Res. Lett. 32, L04807, doi:10.1029/2004GL022080.

Friedrich, K. and Müller, K. 1992. Climate anomalies in Europe associated with ENSO extremes. Int. J. Climatol. 12, 25-31.

Graetbatch, R. J., Lu, J. and Peterson, K. A. 2004. Nonstationary impact of ENSO on Euro-Atlantic winter climate. Geophys. Res. Lett. 31, doi:10.1029/2003GL018542.

Grams, G. and Fiocco, G. 1967. Stratospheric aerosol layer during 1964 and 1965. J. Geophys. Res. 72, 3523-3542.

Hadjinicolaou, P., Pyle, J. A., Chipperfield, M. P. and Kettleborough, J. A. 1997. Effect of interannual meteorological variability on midlatitude O-3. Geophys. Res. Lett. 24, 2993-2996.

Hadjinicolaou, P., Jrrar, A., Pyle, J. A. and Bishop, L. 2002. The dynamically driven long-term trend in stratospheric ozone over northern middle latitudes. Q. J. R. Meteorol. Soc. 128, 1393-1412. 
Harris, N. R. P., Kyro, E., Staehelin, J., Brunner, D., Andersen, S. B. and co-authors. 2008. Ozone trends at northern mid- and high latitudes-a European perspective. Ann. Geophys. 26, 1207-1220.

Hegglin, M. I. and Shepherd, T. G. 2009. Large climate-induced changes in ultraviolet index and stratosphere-to-troposphere ozone flux. Nat. Geosci. 2, 687-691.

Hood, L. L. and Zaff, D. A. 1995. Lower stratospheric stationary waves and the longitude dependence of ozone trends in winter. J. Geophys. Res.-Atmos. 100, 25791-25800.

Hood, L. L. 1997. The solar cycle variation of total ozone: dynamical forcing in the lower stratosphere. J. Geophys. Res.-Atmos. 102, $1355-1370$.

Hood, L. L. and Soukharev, B. E. 2003. Quasi-decadal variability of the tropical lower stratosphere: the role of extratropical wave forcing. $J$. Atmos. Sci. 60, 2389-2403.

Hood, L. L. and Soukharev, B. E. 2005. Interannual variations of total ozone at northern midlatitudes correlated with stratospheric EP flux and potential vorticity. J. Atmos. Sci. 62, 3724-3740.

Hudson, R. D., Andrade, M. F., Follette, M. B. and Frolov, A. D. 2006. The total ozone field separated into meteorological regimes. Part II: Northern Hemisphere mid-latitude total ozone trends. Atmos. Chem. Phys. 6, 5183-5191.

Hurrell, J. W. 1995. Decadal trends in the North-Atlantic Oscillationregional temperatures and precipitation. Science 269, 676-679.

Jaeger, H. and Wege, K. 1990. Stratospheric ozone depletion at northern mid-latitudes after major volcanic eruptions. J. Atmos. Chem. 10, 273-287.

Knudsen, B. M. and Grooss, J. U. 2000. Northern midlatitude stratospheric ozone dilution in spring modeled with simulated mixing. $J$. Geophys. Res.-Atmos. 105, 6885-6890.

Koch, G., Wernli, H., Schwierz, C., Staehelin, J. and Peter, T. 2005. A composite study on the structure and formation of ozone miniholes and minihighs over central Europe. Geophys. Res. Lett. 32, L12810, doi:10.1029/2004GL022062.

Kodera, K. 1994. Influence of volcanic eruptions on the troposphere through stratospheric dynamical processes in the northern-hemisphere winter. J. Geophys. Res.-Atmos. 99, 1273-1282.

Koehler, U. 1995. Homogenization and Re-Evaluation of the Long-Term Ozone Series at the Meteorological Observatory Hohenpeissenberg, Abteilung Forschung Arbeitsergebnisse, 31.

Labitzke, K. G. and van Loon, H. 1999. The Stratosphere. Phenomena, History, and Relevance. Springer, Berlin.

Lau, N. C. 1988. Variability of the observed midlatitude storm tracks in relation to low-frequency changes in the circulation pattern. J. Atmos. Sci. 45, 2718-2743.

Mäder, J. A., Staehelin, J., Brunner, D., Stahel, W. A., Wohltmann, I. and co-authors. 2007. Statistical modeling of total ozone: selection of appropriate explanatory variables. J. Geophys. Res.-Atmos. 112, D11108, doi:10.1029/2006JD007694.

Mäder, J. A., Staehelin, J., Peter, T., Brunner, D., Rieder, H. E. and co-authors. 2010. Evidence for the effectiveness of the Montreal Protocol to protect the ozone layer. Atmos. Chem. Phys. 10, 1216112171.

McCormick, M. P., Thomason, L. W. and Trepte, C. R. 1995. Atmospheric effects of the Mt. Pinatubo eruption. Nature 373, 399-404.

Merkel, U. and Latif, M. 2002. A high resolution AGCM study of the El Niño impact on the North Atlantic/European sector. Geophys. Res. Lett. 29, 1291, doi:10.1029/2001GL013726.
Molina, M. J. and Rowland, F. S. 1974. Stratospheric sink for chlorofluoromethanes-chlorine atomic-catalysed destruction of ozone. Nature 249, 810-812.

Newman, P. A. and Nash, E. R. 2000. Quantifying the wave driving of the stratosphere. J. Geophys. Res.-Atmos. 105, 12485-12497.

Newman, P. A., Nash, E. R. and Rosenfield, J. 2001. What controls the temperature of the arctic stratosphere during the spring? J. Geophys. Res. 106, 19999-20010.

Orsolini, Y. J. and Limpasuvan, V. 2001. The North Atlantic Oscillation and the occurrences of ozone miniholes. Geophys. Res. Lett. 28, 4099-4102.

Orsolini, Y. J. and Doblas-Reyes, F. J. 2003. Ozone signatures of climate patterns over the Euro-Atlantic sector in the spring. Q.J.R. Meteorol. Soc. 129, 3251-3263.

Pawson, S. and Naujokat, B. 1999. The cold winters of the middle 1990s in the northern lower stratosphere. J. Geophys. Res.-Atmos. 104, 14209-14222.

Peter, T. 1997. Microphysics and heterogeneous chemistry of polar stratospheric clouds. Annu. Rev. Phys. Chem. 48, 785-822.

Pickands, J. 1975. Statistical-inference using extreme order statistics. Ann. Stat. 3, 119-131.

Pittock, A. B. 1965. Possible destruction of ozone by volcanic material at 50 mbar. Nature 207, 182, doi:10.1038/207182a0.

Rajewska-Więch, B., Białek, M. and Krzyścin, J. W. 2006. Quality control of Belsk's Dobson spectrophotometer: comparison with the European sub-standard Dobson spectrophotometer and satellite (OMI) overpasses. Publication of the Institute of Geophysics Polish Academy of Sciences, D-67 382, 115-121.

Randel, W. J. and Wu, F. 1999. Cooling of the Arctic and Antarctic polar stratospheres due to ozone depletion. J. Clim. 12, 1467-1479.

Randel, W. J., Wu, F. and Stolarski, R. 2002. Changes in column ozone correlated with the stratospheric EP flux. J. Meteorol. Soc. Japan $\mathbf{8 0}$, 849-862.

Rieder, H. E., Staehelin, J., Maeder, J. A., Peter, T., Ribatet, M. and coauthors. 2010a. Extreme events in total ozone over Arosa-Part 2: fingerprints of atmospheric dynamics and chemistry and effects on mean values and long-term changes. Atmos. Chem. Phys. 10, 10033-10045.

Rieder, H. E., Staehelin, J., Maeder, J. A., Peter, T., Ribatet, M. and co-authors. 2010b. Extreme events in total ozone over Arosa-Part 1: application of extreme value theory. Atmos. Chem. Phys. 10, 10021-10031.

Robock, A. 2000. Volcanic eruptions and climate. Rev. Geophys. 38, 191-219.

Rowland, F. S. and Molina, M. J. 1975. Chlorofluoromethanes in environment. Rev. Geophys. 13, 1-35.

Sato, M., Hansen, J., McCormick, M. and J. Pollack. 1993. Stratospheric Aerosol Optical Depths, 1850-1990. J. Geophys. Res. 98, D12, doi:10.1029/93JD02553, 1993.

Scarnato, B., Staehelin, J., Stubi, R. and Schill, H. 2010. Longterm total ozone observations at Arosa (Switzerland) with Dobson and Brewer instruments (1988-2007). J. Geophys. Res.-Atmos. 115, doi:10.1029/2009JD011908.

Seidel, D. J., Fu, Q., Randel, W. J. and Reichler, T. J. 2008. Widening of the tropical belt in a changing climate. Nat. Geosci. 1, 21-24.

Shepherd, T. G. 2008. Dynamics, stratospheric ozone, and climate change. Atmos.-Ocean 46, 117-138.

Solomon, S. 1999. Stratospheric ozone depletion: a review of concepts and history. Rev. Geophys. 37, 275-316. 
Spaenkuch, D., Schulz, E., Feister, U. and Plessing, P. 1999. Climatology of Total Ozone Measurments 1964 - 1997 at Potsdam, Based on ReEvaluated Dobson Series, Berichte des Deutschen Wetterdienstes. 206.

SPARC-CCMVal 2010. SPARC Report on the Evaluation of ChemistryClimate Models. SPARC Report, (eds V. Eyring, T. G. Shepherd and D. W. Waugh). SPARC Report No. 5, WCRP-132, WMO/TD-No. 1526, http://www.atmosp.physics.utoronto.ca/SPARC.

Staehelin, J., Harris, N. R. P., Appenzeller, C. and Eberhard, J. 2001. Ozone trends: a review. Rev. Geophys. 39, 231-290.

Steinbrecht, W., Claude, H., Kohler, U. and Hoinka, K. P. 1998. Correlations between tropopause height and total ozone: implications for long-term changes. J. Geophys. Res.-Atmos. 103, 19183-19192.

Thompson, D. W. J. and Wallace, J. M. 1998. The Arctic Oscillation signature in the wintertime geopotential height and temperature fields. Geophys. Res. Lett. 25, 1297-1300.

Thompson, D. W. J. and Wallace, J. M. 2000. Annular modes in the extratropical circulation. Part I: month-to-month variability. J. Clim. 13, 1000-1016.

Trenberth, K. E., Branstator, G. W., Karoly, D., Kumar, A., Lau, N. C. and co-authors. 1998. Progress during TOGA in understanding and modeling global teleconnections associated with tropical sea surface temperatures. J. Geophys. Res.-Oceans 103, 14291-14324.

van Loon, H. and Labitzke, K. 1987. The Southern Oscillation. Part V: the anomalies in the lower stratosphere of the Northern Hemisphere in winter and a comparison with the Quasi-Biennial Oscillation. Mon. Weath. Rev. 115, 357-369.

Vaníček, K., Dubrovský, M. and Staněk, M. 2003. Evaluation of Dobson and Brewer total ozone observations from Hradec Králové, Czech Republic, 1961-2002, Publication of the Czech Hydrometeorological Institute, Prague, ISBN: 80-86690-10-5.

Wallace, J. M. 2000. North Atlantic Oscillation/annular mode: two paradigms—one phenomenon. Q. J. R. Meteorol. Soc. 126, 791805.

Waugh, D. W., Oman, L., Kawa, S. R., Stolarski, R. S., Pawson, S. and co-authors. 2009. Impacts of climate change on stratospheric ozone recovery. Geophys. Res. Lett. 36, L03805, doi:10.1029/2008GL036223.

WMO 2003. Scientific Assessment of Ozone Depletion: 2002. Global Ozone Research and Montitoring Project 498.

WMO 2007. Scientific Assessment of Ozone Depletion: 2006. Global Ozone Research and Montitoring Project 572.

Wohltmann, I., Lehmann, R., Rex, M., Brunner, D. and Mader, J. A. 2007. A process-oriented regression model for column ozone. J. Geophys. Res.-Atmos. 112, D12304, doi:10.1029/2006JD007573.

Yue, G. K., McCormick, M. P. and Chiou, E. W. 1991. Stratospheric aerosol optical depth observed by the Stratospheric Aerosol and Gas Experiment: 2. Decay of the El-Chichon and Ruiz volcanic perturbations. J. Geophys. Res.-Atmos. 96, 5209-5219. 